\title{
BUDAYA ORGANISASI DALAM IMPLEMENTASI ENTERPRISE RESOURCES PLANNING PERGURUAN TINGGI DI JAWA TIMUR
}

\section{ORGANIZATIONAL CULTURE IN IMPLEMENTATION ENTERPRISE RESOURCES PLANNING HIGHER EDUCATION IN EAST JAVA}

\author{
Heri Wijayanto \\ Universitas Muhammadiyah Ponorogo \\ E-mail: ok-coi@yahoo.com
}

\begin{abstract}
ABSTRAK
Perubahan pada masyarakat informasi yang berbasis ilmu pengetahuan dan teknologi terjadi di lingkungan perguruan tinggi. Penguasaan ilmu pengetahuan oleh individu dan atau organisasi menjadi modal dasar bagi upaya pengembangan diri dan organisasi dalam situasi yang makin kompetitif. Enterprise Resource Planning (ERP) merupakan solusi mengatasi persaingan global dengan mengintegrasikan semua aktifitas bisnis kedalam system tunggal melalui penggunaan share database. Budaya organisasi dalam implementasi ERP merupakan pola dasar yang diterima oleh organisasi untuk bertindak dan memecahkan masalah, membentuk karyawan beradaptasi dengan lingkungan, dan mempersatukan anggota-anggota organisasi dalam penerapan ERP. Budaya Organisasi diukur melalui karakteristik dominan, tipe kepemimpinan, tipe manajemen, perekat organisasi, penekanan strategi, dan kreteria keberhasilan penerapan ERP. Penelitian ini bertujuan mendiskripsikan budaya organisasi dalam implementasi ERP Perguruan Tinggi di Jawa Timur dengan menggunakan 164 sample yang diambil secara disproportionate stratified sampling. Hasil penelitian menunjukkan pencerminan budaya organisasi dalam implementasi ERP perguruan tinggi di Jawa Timur adalah baik, dan budaya organisasi yang diukur melalui 6 indikator dengan 17 pertanyaan menunjukkan hasil kesesuaian dengan tujuan penelitian yaitu mendiskripsikan budaya organisasi dalam implementasi ERP Perguruan Tinggi di Jawa Timur. Perguruan tinggi perlu meningkatkan aspek budaya organisasi dalam mendukung kesuksesan ERP dari sisi: a). manajemen pengelolaan, b). perekat organisasi melalui loyalitas karyawan pada perguruan tinggi dan implementasi ERP, dan c). strategi untuk mencapai keberhasilan ERP dengan menekankan pada pengembangan system informasi yang mendukung e-literacy.
\end{abstract}

Kata Kunci: Budaya Organisasi, Perguruan Tinggi, Jawa Timur, dan Enterprise Resource Planning

\section{ABSTRACT}

Changes in the information society based on science and technology occur in the tertiary environment. The mastery of knowledge by individuals and or organizations becomes the 
basis for efforts to develop themselves and organizations in increasingly competitive situations. Enterprise Resource Planning (ERP) is a solution to overcome global competition by integrating all business activities into a single system through the use of a share database. Organizational culture in ERP implementation is the basic pattern accepted by organizations to act and solve problems, shape employees to adapt to the environment, and unite organizational members in ERP implementation. Organizational culture is measured through dominant characteristics, leadership types, management types, organizational glue, strategy emphasis, and criteria for successful ERP implementation. This study aims to describe the organizational culture in the implementation of Higher Education ERP in East Java by using 164 samples taken by disproportionate stratified sampling. The results showed the reflection of organizational culture in ERP implementation in tertiary institutions in East Java was good, and organizational culture as measured through 6 indicators with 17 questions showed the results of conformity with research objectives, namely describing organizational culture in the implementation of Higher Education ERP in East Java. Higher education needs to improve aspects of organizational culture in supporting ERP success in terms of: a). management, b). organizational glue through employee loyalty to tertiary institutions and ERP implementation, and c). strategy to achieve ERP success by emphasizing the development of information systems that support e-literacy.

\section{Keywords: Organizational Culture, Higher Education, East Java, and Enterprise Resource Planning}

\section{PENDAHULUAN}

Teknologi informasi sebagai pilar pembangunan nasional, sebagaimana visi teknologi informasi Indonesia yang dinyatakan dalam kalimat "Terwujudnya Indonesia sebagai negara tangguh dalam kompetisi global, melalui pengembangan dan pemanfaatan teknologi informasi dan komunikasi demi terbentuknya masyarakat sejahtera berbasis pengetahuan yang berpegang teguh pada nilai-nilai luhur bangsa" terlihat secara jelas strategi dan harapan diterapkannya teknologi informasi di segala bidang sesuai dengan konteksnya agar dapat tercipta sebuah daya saing nasional (Djokopranoto \& Indrajid, 2010). Perkembangan teknologi informasi dan komunikasi mempunyai dampak yang sangat besar bagi peradaban manusia. Sektor pendidikan menjadi salah satu komunitas yang memiliki tanggung jawab langsung maupun tidak langsung terhadap proses perencanaan, pembangunan, penerapan, dan pengembangan teknologi informasi sesuai dengan tugas dan fungsinya. UNESCO di dalam paparan misinya untuk menciptakan knowledge-based society atau masyarakat berbasis pengetahuan di seluruh dunia.

Tugas perguruan tinggi dalam mempromosikan penggunaan teknologi informasi dengan jalan meningkatkan information literacy masyarakat, yaitu kemampuan seseorang dalam mendayagunakan informasi yang diperolehnya untuk membantu meningkatkan kinerja aktivitas sehari-hari. Information literacy seseorang dalam kategori baik apabila yang bersangkutan dapat melakukan investigasi terhadap informasi apa yang dibutuhkan dalam suatu konteks kondisi tertentu, dapat menyatakannya dalam terminologi yang tepat, dapat melakukan pencarian secara efektif terhadap informasi berkualitas dari berbagai sumber data yang tersedia, dapat melakukan analisa berdasarkan hasil koleksi informasi tersebut, dapat memanfaatkannya untuk berbagai keperluan positif dan mendatangkan value yang signifikan, dan dapat mengolahnya lebih lanjut menjadi sebuah sumber daya pengetahuan (Djokopranoto \& Indrajid, 2010).

Pendidikan tinggi merupakan jenjang pendidikan setelah pendidikan menengah yang mencakup program diploma, program sarjana, program magister, program doktor, dan program profesi, serta program spesialis, yang diselenggarakan oleh perguruan tinggi berdasarkan kebudayaan bangsa Indonesia. Perguruan tinggi merupakan penyelenggara pendidikan yaitu usaha sadar dan terencana untuk mewujudkan suasana belajar dan proses 
pembelajaran agar peserta didik secara aktif mengembangkan potensi dirinya untuk memiliki kekuatan spiritual keagamaan, pengendalian diri, kepribadian, kecerdasan, akhlak mulia, serta keterampilan yang diperlukan dirinya, masyarakat, bangsa, dan negara (UU RI no. 12 tahun 2012).

Pemerintah dalam upaya mewujudkan sistem pendidikan tinggi yang unggul dan berkarakter maka dibentuk lembaga akreditasi independen yang bermartabat, kredibel, dan akuntabel serta menjadi rujukan nasional dan internasional yaitu Badan Akreditasi Nasional Perguruan Tinggi (BAN-PT). Aspek penilaian BAN-PT yang menjadi ukuran yang mengandung kebenaran/kebaikan berkaitan dengan perilaku organisasi yang paling dianut dan menjadi budaya kerja dalam pengambilan keputusan dan pelaksanaan kegiatan meliputi: mutu, integritas, aliansi strategis dan kolaborasi. BAN-PT mensyaratkan penerapan teknologi informasi di perguruan tinggi dalam hal pengelolaan sarana dan prasarana yang menjamin adanya akses yang luas terutama bagi mahasiswa dan dosen, melalui pemanfaatan sumber daya bersama (resource sharing). Sistem informasi perguruan tinggi yang baik tercermin dari kepemilikan blue print yang jelas dalam hal: pengembangan, pengelolaan dan pemanfaatan sistem informasi yang lengkap, serta kepemilikan sistem pendukung pengambilan keputusan (decision support system) yang lengkap, efektif, dan obyektif (BAN-PT, 2011).

Implementasi sistem informasi menjadi tuntutan dan keharusan dalam pengelolaan perguruan tinggi, sehingga investasi di bidang teknologi informasi untuk meningkatkan daya saing, mempermudah pelayanan, dan penjaminan akses yang luas dengan blue print yang jelas menjadi prioritas pengembangan di beberapa perguruan tinggi. Penggunaan system informasi di perguruan tinggi selain karena tuntutan, juga akan mendapat pemeringkatan penilaian pada kemajuan perguruan tinggi terbaik di dunia atau World Class University (WCU), sehingga penting implementasinya.

Pencerminan implementasi ERP perguruan tinggi di antaranya: Sistem Informasi Akademik (Siakad), Sistem Informasi Pengembangan Karir Dosen (SIPKD), Pangkalan Data Pendidikan Tinggi (PDDikti) Simlitabmas, evaluasi diri, portal garuda, e-jurnal, e-learning, dll. PDDikti merupakan salah satu aplikasi ERP yang riil digunakan di perguruan tinggi. PPDikti merupakan proses pencatatan dan penghimpunan data yang diatur dalam Undang-Undang Nomor 12 Tahun 2012 tentang Pendidikan Tinggi (UU Dikti), dan Peraturan Menteri Riset, Teknologi, dan Pendidikan Tinggi (Permenristekdikti) Nomor 61 Tahun 2016 mengatur secara spesifik tentang Pangkalan Data Pendidikan Tinggi (PDDikti). PDDikti dapat mencatat dan mempublikasikan data dalam satu pangkalan data.

Budaya organisasi dalam implementasi sistem informasi dapat menciptakan kohesi antar anggota organisasi, sebagai kontrol sosial, meningkatkan kepuasan semua kolaborator internal perusahaan, memfasilitasi adaptasi lingkungan, dan integrasi internal (Clever, 2001). Budaya organisasi merupakan faktor sukses dalam pengembangan dan implementasi sistem informasi. Penelitian tersebut menunjukkan bahwa budaya organisasi merupakan salah satu factor sukses, dan berperan dalam implementasi system ERP (Indeje \& Zheng, 2010).

Pergeseran masyarakat prainformasional (analog) menuju masyarakat informasional (digital) menuntut perguruan tinggi untuk menerapkan ERP. Mindset karyawan perguruan tinggi dalam memberikan pelayanan dari pelayanan analog menuju digital diharapkan mengikuti perkembangan teknologi. Hambatan terbesar adalah masalah budaya organisasi yang sudah melekat, sehingga perubahan berjalan lambat, dan tidak sebanding dengan kemajuan teknologi yang berakibat pada Information technology paradox's. Perbedaan mendasar antara negara maju dan berkembang dalam intensitas penggunaan ilmu pengetahuan dan teknologi, pada umumnya dikaitkan dengan factor peradaban manusia seperti social, budaya, ekonomi, sejarah, politik, hubungan internasional, dan letak geografis. Penelitian ini penting dilakukan untuk menganalisis factor budaya organisasi yang berperan dalam implementasi ERP Perguruan Tinggi. Hambatan dalam implementasi ERP 
perguruan tinggi diharapkan mampu dijelaskan, sehingga pengambilan keputusan dan strategi dapat dirumuskan untuk menentukan kebijakan implementasi ERP.

Peradaban yang ditopang oleh keberadaan ilmu pengetahuan dan teknologi menjadikan masyarakat modern dengan struktur kehidupan yang dinamis, kreatif untuk melahirkan gagasan-gagasan demi kepentingan manusia dalam berbagai sektor kehidupan, sebagaimana dihasilkan oleh industrialisasi dan teknologisasi. Daya berpikir dan daya cipta semakin berkembang sedemikian rupa sehingga mampu memformulasikan makna kehidupan dalam konteks yang nyata, seterusnya akan berakibat pada bergesernya nilai-nilai budaya yang setiap saat dapat berlangsung walaupun lamban namun pasti (Saefuddin,1990)

Industrialisasi dengan demikian menyangkut proses perubahan sosial, yaitu perubahan susunan kemasyarakatan dari suatu sistem sosial, perubahan dari keadaan negara kurang maju (less developed country) menuju kepada negara maju (more developed country). Penguasaan dan pemanfaatan ilmu pengetahuan dan teknologi merupakan prasyarat untuk memenuhi kebutuhan hidup modern yang sudah memasuki seluruh wilayah kehidupan manusia dan masyarakat bangsa (Saefuddin, 1990).

\section{Budaya Organisasi}

Budaya organisasi merupakan penyebaran kepercayaan dan nilai-nilai yang berkembang dalam suatu organisasi, dan mengarahkan perilaku anggota-anggotanya. Budaya organisasi dapat juga menjadi instruken keunggulan kompetitif yang utama, yaitu bila budaya organisasi dapat menjawab dan mengatasi tantangan lingkungan dengan cepat dan tepat (Soedjono, 2005). Budaya terbentuk dari unsur-unsur ilmu pengetahuan, kepercayaan, seni, moral, hukum, ada istiadat, perilaku/kebiasaan (norma) masyarakat, asumsi dasar, sistem nilai, pembelajaran/pewarisan, masalah adaptasi, dan integrasi internal (Murahartawati, 2013). Moorhead dan Ricky (1999) menyatakan bahwa definisi budaya organisasi merupakan kumpulan nilai-nilai yang membantu anggota organisasi memahami tindakan yang dapat diterima dan yang tidak dapat diterima dalam organisasi.

Budaya organisasi memiliki peran yang strategis untuk mendorong dan meningkatkan efektifitas kinerja organisasi sebagai instumen untuk menentukan arah organisasi, mengarahkan apa yang boleh dilakukan dan yang tidak boleh dilakukan, cara mengalokasikan sumber daya organisasi, dan sebagai alat untuk menghadapi masalah dan peluang dari lingkungan internal maupun ekternal. Budaya organisasi merupakan sistem kontrol sosial bagi anggota organisasi untuk mengendalikan perilaku yang diharapkan agar sesuai dengan tujuan organsasi (Schein, 1997).

Robbins (2003) menjelaskan bahwa budaya organisasi merupakan suatu sistem nilai yang dipegang dan dilakukan oleh anggota organisasi, sehingga membedakan organisasi tersebut dengan organisasi lainnya. Sistem nilai tersebut dibangun oleh 7 (tujuh) karakteristik sebagai sari dari budaya organisasi, yaitu: 1) Inovasi dan pengambilan risiko, 2) Perhatian, 3) Orientasi hasil, 4) Orientasi pada manusia, 5). Orientasi tim, 6) Keagresifan, dan 7) Stabilitas.

Cushway dan Lodge (2000) menyatakan bahwa budaya organisasi merupakan sistem nilai organisasi yang akan mempengaruhi cara pekerjaan dilakukan, dan cara para karyawan berperilaku. Budaya Organisasi menjadi pemersatu anggota, peredam konflik, memotivasi anggota untuk merealisasikan tujuan organisasi dan menciptakan kepuasan kerja. Budaya organisasi yang kuat dapat membuat organisasi menjadi besar.

Aspek budaya dalam pemanfaatan sistem informasi dapat dikelompokkan dalam 4 (empat) domain, yaitu:

a. Budaya sebagai bagian proses implementasi sistem informasi, seperti halnya pandangan user terhadap manfaat yang diberikan oleh sistem informasi, dan persepsi diri pada kemampuan teknis dalam menggunakan sistem informasi (Brown \& Vankatesh, 2005).

b. Budaya sebagai dampak implementasi sistem informasi, yaitu cara penyesuaian diri pengguna terhadap sistem informasi pada face pasca implementasi. Komponen budaya 
pada implementasi sistem informasi meliputi: kestabilan emosi pengguna, perilaku efektif dan efisien dalam bekerja, serta inisiatif untuk ikut serta meminimalkan dampak negative (Beaudry \& Pinsonneault, 2005).

c. Aspek budaya sebagai akselerator, yaitu budaya dapat mengoptimalkan penggunaan sistem informasi dalam melakukan inovasi yang dipengaruhi oleh interpersonal yang terdiri dari: minat pribadi, kemampuan, rasa empati, dan sikap percaya pada teknologi (Ahuja \& Thatcher, 2003).

d. Budaya sebagai penghambat akselerasi sistem informasi (Lapointe \& Ricard, 2005).

Indikator budaya organisasi dalam implementasi ERP (Cameron \& Quinn, 1999) di antaranya: Karakteristik Dominan (karakteristik organisasi), tipe kepemimpinan (konsideran individu, \& stimulan intelektual pimpinan), tipe manajemen (penjaminan rasa aman, keseragaman, \& stabilitas hubungan), perekat organisasi (prestasi \& pencapaian tujuan), penekanan strategi (kompetisi dan prestasi, \& terbentuknya produk baru), dan kriteria keberhasilan (mencapai target, \& adanya inovasi).

\section{PERGURUAN TINGGI}

Lingkup koordinasi Perguruan tinggi di Indonesia di antaranya: Perguruan tinggi Kedinasan di bawah Kementerian, Perguruan tinggi Kedinasan di bawah Lembaga Pemerintah Nonkementerian (badan \& lembaga), Perguruan Tinggi Kedinasan di bawah Kepolisian Negara Republik Indonesia, dan Perguruan Tinggi Kedinasan di bawah Tentara Nasional Indonesia, sedangkan status perguruan tinggi dikelompokkan kedalam status aktif, alih bentuk, hapus, alih kelola, dan non aktif (Forlap.dikti, 2014).

Penyelenggara perguruan tinggi mempunyai kewajiban yang bertanggungjawab untuk menyampaikan data dan informasi penyelenggaraan perguruan tinggi secara sistematis dan berkala kepada kemenristekdikti melalui Pangkalan Data Pendidikan Tinggi (PDDikti) seperti yang diatur dalam Undang-undang Republik Indonesia nomor 12 tahun 2012 tentang Pendidikan Tinggi pasal 56 ayat 1, 2, 3 dan 4 yang berbunyi sebagai berikut:

a. Pangkalan Data Pendidikan Tinggi merupakan kumpulan data penyelenggaraan pendidikan tinggi seluruh perguruan tinggi yang terintegrasi secara nasional,

b. Pangkalan Data Pendidikan Tinggi sebagaimana dimaksud pada ayat 1 berfungsi sebagai sumber informasi bagi:

- Lembaga akreditasi, untuk melakukan akreditasi program studi dan perguruan tinggi.

- Pemerintah, untuk melakukan pengaturan, perencanaan, pengawasan, pemantauan, dan evaluasi serta pembinaan dan koordinasi program studi dan perguruan tinggi.

- Masyarakat, untuk mengetahui kinerja program studi dan perguruan tinggi.

c. Pangkalan Data Pendidikan Tinggi dikembangkan dan dikelola oleh Kementerian atau dikelola oleh lembaga yang ditunjuk oleh Kementerian.

d. Penyelenggara perguruan tinggi wajib menyampaikan data dan informasi penyelenggaraan perguruan tinggi serta memastikan kebenaran dan ketepatannya.

Data perguruan tinggi berdasarkan PDDikti tahun 2014 berjumlah 4.757 yang terdiri dari 1.351 akademi, 253 politeknik, 2.497 sekolah tinggi, 1.109 institut, dan 537 universitas. Perguruan tinggi mayoritas berada dalam lingkup koordinasi kemenristekdikti, yaitu sebanyak 3.589, dalam lingkup koordinasi kementerian agama sebanyak 1.000, dalam lingkup koordinasi kementerian lainnya sebanyak 158, dalam lingkup koordinasi Lembaga Pemerintah Nonkementerian sebanyak 8, dan Perguruan Tinggi Kedinasan di bawah Kepolisian Negara Republik Indonesia, dan Tentara Nasional Indonesia sebanyak 2 (Forlap.dikti, 2014). 


\section{ERP DI PERGURUAN TINGGI}

BAN-PT (2011) mensyaratkan standar sistem informasi perguruan tinggi harus memiliki sistem informasi yang disiapkan untuk mendukung pengelolaan dan peningkatan mutu program akademik. Sistem informasi dalam suatu perguruan tinggi minimal terdiri atas pengumpulan data, analisis data, penyimpanan, pengambilan data kembali (retrieval), presentasi data dan informasi, serta komunikasi dengan pihak yang berkepentingan. Data dan informasi yang dikelola oleh perguruan tinggi dapat meliputi akademik, kemahasiswaan, sumberdaya manusia, prasarana dan sarana administrasi dan keuangan serta data lain yang dianggap perlu untuk kepentingan berbagai pihak. Dalam berbagai hal, perguruan tinggi harus dapat memanfaatkan sistem informasi yang dimilikinya untuk memelihara komunikasi dan koordinsi internal serta kerjasama dengan institusi lain, pemerintah, alumni, perusahaan/industri atau masyarakat luas (BAN-PT, 2011).

Perkembangan teknologi informasi yang sangat cepat maka perguruan tinggi harus mampu melakukan pengelolaan yang profesional serta pemutahiran terhadap piranti keras dan lunak, sumber daya manusia serta organisasi pengelola untuk menjamin pertumbuhan sistem informasi yang telah dibangun tersebut. Perguruan tinggi juga harus menjamin akses bagi mahasiswa, staf dan sivitas akademika lainnya untuk memanfaatkan keberadaan sistem informasi tersebut melalui peraturan-peraturan yang transparan (BAN-PT, 2011).

Standar sistem informasi perguruan tinggi dinilai dari beberapa elemen penilaian yang telah ditetapkan oleh BAN-PT, yang meliputi:

a. Perguruan tinggi memiliki blue print yang jelas tentang pengembangan, pengelolaan dan pemanfaatan sistem informasi termasuk sistem yang mengatur aliran data, otorisasi akses data, dan sistem disaster recovery.

b. Perguruan tinggi memiliki sistem pendukung pengambilan keputusan (dicision support system) membantu pimpinan dalam melakukan perencanan dan analisa evaluasi diri dengan baik dan pengambilan keputusan yang lebih obyektif.

c. Sistem informasi yang dimiliki berupa basis data dan informasi yang minimal mecakup keuangan perguruan tinggi, aset, sarana dan prasarana, administrasi akademik, profil mahasiswa dan lulusan, dosen dan tenaga pendukung.

d. Perguruan tinggi memiliki sistem informasi yang dimanfaatkan untuk komunikasi internal dan eksternal kampus serta akses bagi mahasiswa dan dosen pada sumbersumber informasi ilmiah.

e. Perguruan tinggi memiliki kapasitas internet dengan rasio bandwidth per mahasiswa yang memadai.

\section{IMPLEMENTASI ERP DI PERGURUAN TINGGI}

Perangkat lunak yang mencerminkan implementasi ERP perguruan tinggi salah satunya adalah PPDikti Feeder yang berfungsi sebagai perangkat lunak yang ditempatkan di perguruan tinggi dan memiliki struktur basis data replika dari basis data perguruan tinggi yang digunakan sebagai sarana pelaporan resmi penyelenggaraan pendidikan tinggi seluruh perguruan tinggi (Djokopranoto \& Indrajid, 2010).

Kehadiran aplikasi PDDikti Feeder berdampak positif bagi pengelolaan data yang dilaporkan setiap perguruan tinggi. Pertumbuhan perguruan tinggi dari tahun ke tahun, rasio mahasiswa dan dosen, klasifikasi perguruan tinggi negeri dan swasta, status perguruan tinggi, dan jumlah profesor dapat termonitor oleh stake holder. PDDikti juga terintegrasi ke instrumen sertifikasi profesi, seperti uji kompetensi dokter indonesia, Uji kompetensi akuntan indonesia, dan uji kompetensi guru.

Sehimpun data yang telah dipetakan Pusdatin Kemenristekdikti dapat menjadi salah satu sumber informasi. Data yang telah dianalisis dapat menjadi rujukan bagi mahasiswa, calon mahasiswa, dosen, perguruan tinggi, bahkan publik dan institusi lain untuk melihat bagaimana direktori serta keadaan konkret pendidikan tinggi Indonesia saat ini. Teknologi informasi dan komunikasi, serta masyarakat berbasis pengetahuan menyebabkan perubahan 
paradigma penyelenggaraan pendidikan tinggi tidak dapat ditawar lagi. Fokus utama kinerja Kemenristekdikti tetap pada upaya mempersiapkan generasi yang akan bersaing dalam pasar kerja nasional maupun internasional, serta akan memenuhi beragam kesempatan kerja. Reformasi tersebut antara lain berupa penyediaan pendidikan yang fleksibel dan berorientasi pada peserta didik serta pangsa pasar, perubahan kurikulum, penyediaan dosen, guru besar, maupun tenaga kependidikan yang profesional (Djokopranoto \& Indrajid, 2010).

Beaudry dan Pinsonnneault (2005) menyatakan bahwa budaya organisasi dalam implementasi sistem informasi merupakan cara penyesuaian diri pengguna pada sistem informasi. Dengan demikian semakin baik budaya organisasi dalam implementasi ERP akan meningkatkan keuntungan individu, dan keuntungan organisasi (hasil maksimal, efektif, efisien akuntabilitas, mengurangi beaya operasional, dan meningkatkan daya saing perusahaan). Ahuja dan Thatcher (2003) menyatakan bahwa budaya dapat mengoptimalkan penggunaan sistem informasi dalam melakukan inovasi yang dipengaruhi oleh interpersonal yang terdiri minat pribadi, kemampuan, rasa empati, serta sikap percaya pada teknologi, dan Lamb dan Kling (2003) menyatakan bahwa pemanfaatan sistem informasi sangat dipengaruhi oleh budaya organisasi yang berasal dari tradisi dan kebiasaan individu.

\section{METODE PENELITIAN}

\section{Batasan dan Lokasi Penelitian}

Penelitian ini dilakukan pada perguruan tinggi di Jawa Timur dengan pertimbangan Jawa Timur merupakan sebuah provinsi di bagian timur Pulau Jawa Indonesia yang terbagi dalam 29 kabupaten, dan 9 kota (BPS Jawa Timur, 2010), dan menurut PDDikti tahun 2015 di Jawa Timur terdapat 474 perguruan tinggi, jumlah tersebut merupakan jumlah terbanyak perguruan tinggi di Indonesia dalam satu provinsi (Forlap.dikti.go.id, 2015).

\section{Jenis Penelitian}

Penelitian ini adalah jenis penelitian survey, yaitu mengkaji populasi (universe) yang besar dengan menyeleksi serta mengkaji sampel yang dipilih dari populasi untuk menemukan distribusi, dan interelasi relatif dari variabel-variabel (Kerlinger, 2004). Secara spesifik dikategorikan kedalam penelitian survey analitik yaitu melakukan pengamatan atau penyelidikan yang kritis untuk mendapatkan keterangan yang terang dan baik pada suatu persoalan tertentu, dan di dalam suatu daerah tertentu yang bertujuan untuk mencapai generalisasi dan analisis (Soehartono, 2000).

\section{Populasi, Sampel, dan Unit Analisis}

Populasi penelitian ini adalah perguruan tinggi di Jawa Timur baik Perguruan Tinggi Negeri (PTN) maupun Perguruan Tinggi Swasta (PTS) yang berada dalam lingkup koordinasi Kemeterian Riset Teknologi, dan Pendidikan Tinggi (kemenristekdikti), dan berstatus aktif yaitu sebanyak 285, hal ini dikarenakan penataan sistem informasi perguruan tinggi dalam lingkup koordinasi kemenristekdikti sudah mencerminkan penerapan sistem ERP, sementara pada perguruan tinggi dalam lingkup koordinasi selain kemenristekdikti implementasi ERP belum sepenuhnya terintegrasi pada satu pangkalan data/data base. Perguruan tinggi berstatus aktif yang dipilih karena hanya perguruan tinggi yang berstatus aktif yang melakukan standarisasi pengelolaan sistem informasi yang disyaratkan BAN-PT.

Teknik sampling menggunakan disproportionate stratified sampling, dengan alasan pengelolaan sistem informasi di perguruan tinggi dapat distratakan ke dalam 2 (dua) strata yaitu: perguruan tinggi berperingkat dan tidak berperingkat di webometrics (Webometrics merupakan salah satu perangkat atau sistem untuk mengukur atau memberikan penilaian pada kemajuan perguruan tinggi terbaik di dunia melalui Website perguruan tinggi, bertujuan untuk meyakinkan komunitas akademik dan politik mengenai pentingnya publikasi web yang tidak hanya bisa untuk diseminasi pengetahuan akademik, melainkan juga untuk 
mengukur aktivitas ilmiah, kinerja dan imbasnya). Berdasarkan pemeringkatan webometrics perguruan tinggi di Jawa Timur yang berada dibawah lingkup koordinasi kemenristekdikti, sebanyak 57 berperingkat, dan sebanyak 228 tidak berperingkat, sehingga populasi berstrata tetapi tidak proporsional. Unit analisis yang digunakan dalam penelitian ini adalah organisasi, dengan alat analisis Structural Equation Modelling (SEM) dengan software Amos 22.

\title{
HASIL DAN PEMBAHASAN
}

Confirmatory Factor Analysis (CFA) konstruk budaya organisasi (BO) merupakan tahap pengukuran pada dimensi-dimensi yang membentuk variabel laten pada konstruk. Variabel BO diukur dengan 6 (lima) indikator yaitu: karakteristik dominan (BO1), tipe kepemimpinan (BO2), tipe manajemen (BO3), perekat organisasi (BO4), penekanan strategi (BO5), dan kriteria keberhasilan (BO6). Hasil estimasi model pengukuran sebagaimana pada Gambar 1.

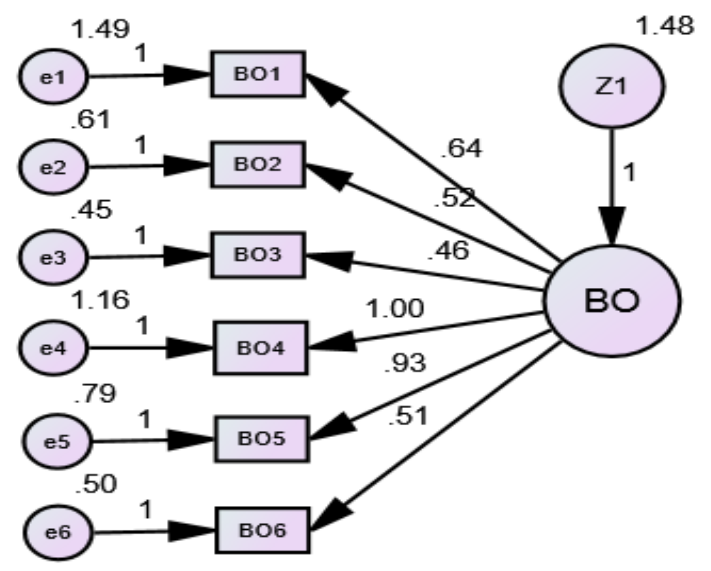

\author{
chi-square $=24.982$ \\ df $=9$ \\ $\mathrm{cmin} / \mathrm{df}=2.776$ \\ $\mathrm{AGFI}=.883$ \\ $\mathrm{GFI}=.950$ \\ $\mathrm{TLI}=.916$ \\ $\mathrm{CFI}=.950$ \\ RMSEA $=.104$
}

Gambar 1. Estimasi Model Pengukuran Budaya Organisasi

Estimasi model pengukuran konstruk budaya organisasi sebagaimana Gambar 1 menginformasikan bahwa model pengukuran untuk konstruk budaya organisasi yang dispesifikasi dalam data ini secara keseluruhan konsisten dan fit dengan data, nilai Chisquare $=24,982$ mendekati nilai dari chi-square Tabe/ pada $a=0,05$ dan $\mathrm{df}=9$ adalah 16,92, hal ini menunjukkan bahwa matrik kovarians sampel signifikan dengan matrik kovarians yang diestimasi dalam model.

Nilai RMSEA = 0,104 menunjukkan bahwa nilainya mendekati goodness of fit seperti yang disarankan (Hair et al. 2010) yaitu < 0,08, dan bahwa kesenjangan disperancy antara matrik kovarians sampel dengan matrik kovarians yang diestimasi dalam model per derajat kebebasan ( $d f=$ degree of freedom) tipis. Ringkasan hasil uji kesesuaian model tersaji dalam Tabel 1.

Tabel 1. Hasil Uji Kesesuaian Model pada Konstruk Budaya Organisasi

\begin{tabular}{llrl}
\hline \multicolumn{1}{c}{ Goodness of Fit Index } & \multicolumn{1}{c}{ Cut-off value } & Hasil & \multicolumn{1}{c}{$\begin{array}{c}\text { Evaluasi } \\
\text { Model }\end{array}$} \\
\hline Degree of freedom (df) & $<$ dari chi-square Tabel pada & 24.982 & Marginal \\
Chi-square & $\begin{array}{l}\text { df }=9(16.92) \\
\text { S2.00 }\end{array}$ & 2.776 & Marginal \\
Cmin/df & $\geq 0.90$ & .883 & Marginal \\
AGFI & $\geq 0.90$ & .950 & Baik \\
GFI & $\geq 0.95$ & .916 & Baik \\
TLI & $\geq 0.95$ & .950 & Baik \\
CFI & $\leq 0.08$ & .104 & Marginal \\
RMSEA & & & \\
\hline
\end{tabular}


Ringkasan hasil uji kesesuaian model konstruk budaya organisasi sebagaimana Tabel 1 dapat disimpulkan bahwa semua konstruk yang digunakan untuk membentuk sebuah model telah memenuhi kreteria goodness of fit yang telah ditetapkan. Evaluasi pengaruh antar konstruk dengan indikator-indikatornya (Loading Factor) dengan kriteria-kriteria Overall Measurement Fit Model dari masing-masing dimensi, dapat dijelaskan jika diperoleh hasil pengujian yang significant $(<0,05)$, maka hasil tersebut mengindikasikan bahwa dimensi budaya organisasi cukup baik untuk terekstrasi membentuk variabel. Hasil pengujian pengaruh antar konstruk (regression weight) dalam membentuk variabel sebagaimana dalam Tabel 2.

Tabel 2. Regression Weight Konstruk Budaya Organisasi

\begin{tabular}{lllrrrr}
\hline & & \multicolumn{1}{c}{ Estimate } & S.E. & C.R. & P \\
\hline BO4 & $<---$ & BO & 1.000 & & & \\
BO3 & $<---$ & BO & .464 & .061 & 7.553 & $* * *$ \\
BO2 & $<--$ & BO & .519 & .071 & 7.261 & $* * *$ \\
BO1 & $<---$ & BO & .645 & .100 & 6.446 & $* * *$ \\
BO5 & $<---$ & BO & .931 & .101 & 9.189 & $* * *$ \\
BO6 & $<---$ & BO & .506 & .066 & 7.709 & $* * *$ \\
\hline
\end{tabular}

Hasil pengujian pengaruh antar konstruk dalam Tabel 2 menunjukkan bahwa hasil analisis setiap indikator atau dimensi pembentuk masing-masing variabel menunjukkan hasil yang baik, yaitu nilai dengan CR diatas 1,96 , dan probabilitas yang lebih kecil dari 0,05, dengan hasil pengujian tersebut maka dapat dijelaskan bahwa indikator pembentuk variabel telah menunjukkan unidimensionalitas, dan model dapat digunakan untuk analisis selanjutnya tanpa modifikasi atau penyesuaian.

Hasil CFA pada konstruk budaya organisasi menunjukkan bahwa 6 (enam) indikator, yaitu karakteristik dominan, tipe kepemimpinan, tipe manajemen, perekat organisasi, penekanan strategi, dan kreteria keberhasilan mempunyai kontribusi dalam membentuk kontruk budaya organisasi. Tingkat signifikansi pada toleransi 0,05, yang diukur dengan menggunakan regression weight kontruk budaya organisasi sebagaimana Tabel 2, menunjukkan hasil $P$ value bernilai 0,000 pada semua pertanyaan penyusun kontruk. Hal ini mengindikasikan bahwa semua pertanyaan mempunyai hubungan yang erat, dan signifikan dalam membentuk kontruk budaya organisasi.

\section{Distribusi Jawaban Responden untuk Variabel Budaya Organisasi}

Variabel budaya organisasi diukur dari 6 (enam) indikator dijabarkan kedalam 17 (tujuh belas) butir pertanyaan (B1 s/d B17), adapun hasil distribusi frekuensi sebagaimana dalam Tabel 3.

Tabel 3. Distribusi Skor Jawaban Resonden tentang Variabel Budaya Organisasi

\begin{tabular}{|c|c|c|c|c|c|c|c|c|c|c|c|}
\hline \multirow{3}{*}{ Item } & \multicolumn{10}{|c|}{ SKOR } & \multirow{3}{*}{ Mean } \\
\hline & \multicolumn{2}{|c|}{1 (STS) } & \multicolumn{2}{|c|}{2 (TS) } & \multicolumn{2}{|c|}{$3(C S)$} & \multicolumn{2}{|c|}{$4(S)$} & \multicolumn{2}{|c|}{5 (SS) } & \\
\hline & $f$ & $\%$ & $f$ & $\%$ & $f$ & $\%$ & $f$ & $\%$ & $f$ & $\%$ & \\
\hline B1 & 11 & 2.2 & 94 & 19.1 & 121 & 24.6 & 188 & 38.2 & 78 & 15.9 & 3.46 \\
\hline B2 & 13 & 2.6 & 85 & 17.3 & 139 & 28.3 & 206 & 41.9 & 49 & 10 & 3.39 \\
\hline B3 & 2 & 0.4 & 64 & 13 & 148 & 30.1 & 214 & 43.5 & 64 & 13 & 3.56 \\
\hline B4 & 13 & 2.6 & 66 & 13.4 & 145 & 29.5 & 199 & 40.4 & 69 & 14 & 3.49 \\
\hline B5 & 27 & 5.5 & 65 & 13.2 & 162 & 32.9 & 177 & 36 & 61 & 12.4 & 3.36 \\
\hline B6 & 22 & 4.5 & 80 & 16.3 & 154 & 31.3 & 172 & 35 & 64 & 13 & 3.35 \\
\hline B7 & 8 & 1.6 & 62 & 12.6 & 168 & 34.1 & 195 & 39.6 & 59 & 12 & 3.48 \\
\hline B8 & 9 & 1.8 & 71 & 14.4 & 155 & 31.5 & 200 & 40.7 & 57 & 11.6 & 3.46 \\
\hline B9 & 15 & 3 & 83 & 16.9 & 151 & 30.7 & 193 & 39.2 & 50 & 10.2 & 3.37 \\
\hline B10 & 11 & 2.2 & 67 & 13.6 & 162 & 32.9 & 178 & 36.2 & 74 & 15 & 3.48 \\
\hline B11 & 16 & 3.3 & 61 & 12.4 & 153 & 31.1 & 192 & 39 & 70 & 14.2 & 3.49 \\
\hline
\end{tabular}




\begin{tabular}{rrrrrrrrrrrr} 
B12 & 27 & 5.5 & 73 & 14.8 & 121 & 24.6 & 202 & 41.1 & 69 & 14 & 3.43 \\
B13 & 21 & 4.3 & 76 & 15.4 & 128 & 26 & 199 & 40.4 & 68 & 13.8 & 3.44 \\
B14 & 16 & 3.3 & 77 & 15.7 & 133 & 27 & 199 & 40.4 & 67 & 13.6 & 3.45 \\
B15 & 37 & 7.5 & 51 & 10.4 & 114 & 23.2 & 212 & 43.1 & 78 & 15.9 & 3.49 \\
B16 & 23 & 4.7 & 60 & 12.2 & 134 & 27.2 & 201 & 40.9 & 74 & 15 & 3.49 \\
B17 & 20 & 4.1 & 54 & 11 & 128 & 26 & 223 & 45.3 & 67 & 13.6 & 3.53 \\
\hline
\end{tabular}

Tabel 3 menunjukkan distribusi, dan persentase jawaban responden dengan nilai rerata untuk variabel budaya organisasi. Nilai rerata jawaban responden terendah sebesar 3.35 untuk pertanyaan keenam yaitu pimpinan menuntut hasil kerjaan secara maksimal, hal ini menunjukkan bahwa perguruan tinggi menuntut capaian hasil secara maksimal dengan penerapan ERP, karena perguruan tinggi pelaporan secara digital melalui program feeder harus dilakukan secara benar, tepat waktu, terus menerus, dan di validasi oleh pimpinan.

Karakteristik dominan di perguruan tinggi yang diukur melalui: seperti keluarga besar yang saling berbagi satu sama lainnya diperoleh nilai mean 3.46, merupakan tempat bekerja yang menyenangkan diperoleh nilai mean 3.39, adanya standart operating procedure (SOP) dalam bekerja diperoleh nilai mean 3.56, bercirikan kerja tim diperoleh nilai mean 3.49. Hasil ini menunjukkan bahwa pencerminan karakteristik dominan peguruan tinggi mempunyai percerminan yang tinggi, ditandai dengan nilai mean semua item pertanyaan diatas rata-rata.

Tipe kepemimpinan perguruan tinggi, yang diukur melalui: pimpinan berani mengambil resiko dalam implementasi ERP diperoleh nilai mean 3.36, pimpinan menuntut hasil kerja secara maksimal diperoleh nilai mean 3.35, hal ini menunjukkan tipe kepemimpinan perguruan tinggi di Jawa Timur mendukung pengembangan ERP, ditandai dengan nilai mean diatas rata-rata.

Tipe manajemen perguruan tinggi, yang diukur melalui: memberikan jaminan kesehatan kepada karyawan diperoleh nilai mean 3.48, dan memberikan jaminan keselamatan kepada karyawan diperoleh nilai mean 3.46. Hasil ini menunjukkan bahwa tipe manajemen perguruan tinggi mendukung implementasi ERP, karena implementasi ERP membutuhkan jaminan atau service quality bagi user, key user, dan end user yang menjamin keberlanjutan ERP.

Perekat organisasi perguruan tinggi, yang diukur melalui: pimpinan menjaga stabilitas hubungan antar personal diperoleh nilai mean 3.37, kepercayaan bersama selalu dijaga diperoleh nilai mean 3.48, memberikan penghargaan atas prestasi diperoleh nilai mean 3.49, dan memberikan sanksi atas kesalahan diperoleh nilai mean 3.43. Hasil analisis ini menunjukkan adanya keserasian antara karyawan dan perekat organisasi dalam implementasi ERP.

Penekanan strategi perguruan tinggi, yang diukur melalui: menekankan pada pengembangan SDM diperoleh nilai mean 3.45, menekankan pada pengembangan ERP diperoleh nilai mean 3.44, dan menekankan pada hasil diperoleh nilai mean 3.49. Hasil analisis ini menunjukkan adanya orientasi perguruan tinggi pada hasil, hal ini sejalan dengan implementasi ERP yang menekankan pada kualitas dan kuantuitas hasil atau output.

Kreteria keberhasilan perguruan tinggi, yang diukur melalui: menetapkan target capaian dalam pengembangan ERP diperoleh nilai mean 3.49, dan keberhasilan dilihat dari inovasi yang telah dilakukan diperoleh nilai mean 3.53. Hasil analisis menunjukkan target capaian, dan inovasi yang dilakukan perguruan tinggi dibidang ERP menunjukkan hasil yang baik yang ditandai dengan terpenuhinya standart penerapan teknologi informasi di perguruan tinggi oleh BAN-PT.

Nilai mean tertinggi sebesar 3.56 untuk pertanyaan ketiga yaitu di perguruan tinggi ada standart operating prosedure (SOP) dalam bekerja. Sistem penjaminan mutu perguruan tinggi meliputi kebijakan mutu, perangkat penjaminan mutu (organisasi, pernyataan mutu, manual mutu, standar mutu), pelaksanaan penjaminan mutu, serta monitoring dan evaluasi. Keberadaan manual mutu yang mencakup informasi tentang kebijakan, pernyataan, unit pelaksana, standar, prosedur, SOP, dan pentahapan sasaran mutu perguruan tinggi merupakan salah satu isian borang yang dipenuhi dalam pengajuan akreditasi institusi perguruan tinggi ke BAN-PT. Keberadaan SOP harus diunggah dalam sistem, hal ini membuktikan bahwa pentingnya sistem informasi dalam mendukung tata kelola perguruan tinggi yang tercermin dalam budaya organisasi.

\section{KESIMPULAN}

Kesimpulan dari penelitian ini adalah: pencerminan budaya organisasi dalam implementasi ERP perguruan tinggi di Jawa Timur adalah baik, dan budaya organisasi yang diukur melalui 6 indikator 
dengan 17 pertanyaan menunjukkan hasil kesesuaian dengan tujuan penelitian yaitu mendiskripsikan budaya organisasi dalam implementasi ERP Perguruan Tinggi di Jawa Timur.

Saran yang diberikan kepada perguruan tinggi di Jawa Timur adalah: perlu merubah paradigma dalam use ERP dari bersifat mandatori ke adoption intention (kebutuhan) sehingga pemanfaatannya penuh tanggungjawab dan melaksanakan dengan sukarela. Perguruan tinggi perlu meningkatkan aspek budaya organisasi dalam mendukung kesuksesan ERP dari sisi: a). manajemen pengelolaan, b). perekat organisasi melalui loyalitas karyawan pada perguruan tinggi dan implementasi ERP, dan c). strategi untuk mencapai keberhasilan ERP dengan tolok ukur yang jelas misalnya pemeringkatan webometrics, TeSCA, 4ICU, dan QS Rangking. Budaya organisasi berperan dalam kesuksesan implementasi ERP perguruan tinggi, sementara pemeringkatan penggunaan sistem informasi yang dilakukan webometrics, dan Unesco menempatkan Indonesia pada permasalahan digital divide, sehingga perlunya perguruan tinggi menekankan pada pengembangan system informasi yang mendukung e-literacy.

Penggunaan ERP perguruan tinggi di Indonesia terus bertambah, Modul ERP berkembang sesuai dengan tuntutan perguruan tinggi, pemeringkatan aktifitas system informasi semakin banyak, namun diindikasikan bahwa sebagian perguruan tinggi mengalami gagal implementasi ERP, oleh karena perlunya analisis kesuksesan ERP dengan mempertimbangkan pemeringkatan perguruan tinggi.

Merekomendasikan pada peneliti selanjutnya untuk mempertimbangkan peran perguruan tinggi dalam mewujudkan pilar pembangunan nasional di bidang teknologi informasi melalui ERP, karena salah satu tugas perguruan tinggi salah satunya adalah meningkatkan information literacy masyarakat.

\section{DAFTAR PUSTAKA}

Ahuja, M. K., J. B. Thatcher, 2005, "Moving Beyond Intentions and Toward the Theory of Trying: Effects of Work Environment and Gender on Post-Adoption Information Technology Use", MIS Quarterly, vol. 29, no 3, pp. 427-460.

BAN-Perguruan Tinggi, 2011, Kumpulan instrument standart 11 sistem informasi Perguruan Tinggi, Departemen pendidikan Nasional.

Beaudry, A., Pinsoneault A., 2005, "Understanding User Responses to Information Technology: A Coping Model of User Behavior", MIS Quarterly, vol. 29, no. 3, pp. 493-525.

Brown, S., Venkatesh V, 2005, "Model of adoption technology in households: a baseline model test extension incorporating household life cycle", MIS Quarterly, vol. 27, no. 3, pp. 479-501.

Cameron and Quinn, 1999, Diagnosing and changing organizational culture: Based on the competing value framework reading, Massachusetts, addison-wesley publishing company, inc.

Clever, E., Llopis, J., Gonzalez, M.R., and Gasco, J.L, 2001, "The performance of information system through organizational Culture Information Technology and People", vol. 14, No. 3, pp. 247-260.

Cushway, Barry \& Derek Lodge, 2000, Organizational Behaviour And Design, Jakarta: Elex Media Computindo.

Djokopranoto R., dan Indrajid R., E., 2010, Manajemen Perguruan Tinggi Modern, Sekolah Tinggi Manajemen Informatika dan Komputer Perbanas, dan Yayasan Atma Jaya, Jakarta. 
Indeje, Wanyama G., dan Zheng, 2010, "Organizational Culture and Information Systems Implementation: AStructuration Theory Perspective", Working Papers on Information Systems, vol. 10, no 27, ISSN 1535-6078.

Kerlinger, Fred N., 2004, Asas-asas Penelitian Behavioral, Yogyakarta: UGMPress.

Lapointe, L., S. Rivard, 2005, "A Multilevel Model of Resistance to Information Technology Implementation", MIS Quarterly, vol. 29, no 3, pp. 461-492.

Moorhead, G., and Ricky, W.G., 1999, Human Resources Management, New York: Prentice Hall, Inc.

Murahartawati, 2013, "Analisis pengaruh budaya organisasi pada efektifitas imlementasi sistem informasi", seminar nasional aplikasi teknologi informasi (SNATI), Yogyakarta, Juni, pp. 21-28.

Robbins, S.P, 1997, Organizational Behavior: Concept, Controversies, and Applications, 6th Edition, Englewood Cliffs, Prentise Hall International, New Jersey.

Saefuddin, AM. Desekularisasi Pemikiran Landasan Islamisasi. Bandung: Mizan, 1990

Schein, Edgar H,. 2004, Organizational Culture and Leadership Third Edition, Jossey-Bass, A Wiley Imprint, Market Street, San Fransisco.

Soedjono, 2005, "Pengaruh Budaya Organisasi Terhadap Kinerja Organisasi dan Kepuasan Kerja Karyawan pada Terminal Penumpan Umum di Surabaya", Jurnal Ekonomi Manajemen, Fakultas Ekonomi, Universitas Kristen Petra.

Soehartono dan Irawan, 2000, Metode Penelitian Sosial: Suatu teknik penelitian bidang kesejahteraan social dan ilmu social lain, Bandung: PT Remaja Rosdakarya.

Undang-Undang Republik Indonesia nomor 12 tahun 2012, tentang Pendidikan Tinggi. 